\title{
FAKTOR-FAKTOR YANG MEMPENGARUHI PREFERENSI MASYARAKAT DALAM MENGGUNAKAN MODA MASS RAPID TRANSIT (MRT) KOTA JAKARTA
}

\author{
Mochamad Trias Sembada*, Septiana Hariyani, Deni Agus Setyono \\ Jurusan Perencanaan Wilayah dan Kota, Fakultas Teknik, Universitas Brawijaya \\ J1. Mayjen Haryono 167 Malang 65141 - Telp (0341)567886 \\ *e-mail: trias.sembada2796@gmail.com
}

\begin{abstract}
ABSTRAK
DKI Jakarta selain merupakan Ibukota Negara Indonesia jugamenjadi pusat bisnis dan pemerintahan dengan jumlah penduduk mencapai 10.374.235 jiwa dan kepadatan penduduk mencapai 15.663 orang per $\mathrm{km}^{2}$. Dinamika kota-kota besar dengan karakter pertumbuhan penduduk dan kepadatan lalu lintas yang tinggi membuat kebutuhan terhadap pengembangan sistem transportasi terutama transportasi massal cepat (Mass Rapid Transportation-MRT) menjadi cukup besar. Selain itu, pengembangan sistem transportasi ini juga untuk mengimbangi pertumbuhan kendaraan pribadi yang terus mengalami peningkatan, sedangkan sistem moda shares angkutan umum cenderung mengalami penurunan hingga $3 \%$ sejak tahun 2002. Saat ini, terdapat upaya pengembangan sistem angkutan umum massal berbasis jalan dan berbasis rel berdasarkan RTRW DKI Jakarta 2010-2030. Berkaitan dengan kondisi tersebut perlu adanya kajian terhadap penilaian pelayanan transportasi umum guna menarik masyarakat dalam menggunakannya agar permasalahan lalu lintas yang ada dapat terselesaikan. Tujuan penelitian ini antara lain adalah mengetahui karakteristik masyarakat yang memiliki preferensi dalam menggunakan moda MRT dan faktor-faktor yang mempengaruhi preferensi masyarakat dalam menggunakan moda MRT. Penelitian ini menggunakan metode analisis statistic deskriptif dan analisis faktor. Berdasarkan hasil analisa diketahui masyarakat yang memiliki preferensi untuk menggunakan moda MRT sebesar $98 \%$ dengan karakter sebagian besar berjenis kelamin Laki-laki, rentang usia 25-35 Tahun, jenis pekerjaan pegawai swasta, dan tingkat penghasilan $\geq$ Rp.4.000.000. Tujuan perjalanan menuju perkantoran, dan memiliki keperluan perjalanan untuk bekerja. Selanjutnya dari analisis faktor dihasilkan 17 kelompok faktor yang mempengaruhi preferensi masyarakat dalam menggunakan moda MRT, dengan kelompok faktor nomor 1 yang memiliki tingkat variasi eigen value tertinggi.
\end{abstract}

Kata kunci: Preferensi, Analisis Faktor, Mass Rapid Transit

\section{ABSTRACT}

Jakarta city is the Capital City of Indonesia and also the center of business and government with a population of 10,374,235 people within population density of 15,663 people for $\mathrm{km}^{2}$. The dynamics cities character is a growing population and high traffic density, as of situation purpose the city need for the some of transportation system, especially fast mass transportation (Mass Rapid Transportation-MRT), to be quite large. Also, the development of this transportation system is to balance the growth of private vehicles which continues to increase, while the public transportation share mode system has tended to decline by 3\% since 2002. Currently, there are efforts to develop a road-based and rail-based mass public transport system based on RTRW DKI Jakarta 2010-2030. With this condition, it is necessary to study the assessment of public transportation services to attract the public to use them so that existing traffic problems can be resolved. The purpose of this study is to determine the characteristics of people who have a preference in using the MRT mode and the factors that influence people's preferences for using the MRT mode. This study uses descriptive statistical analysis methods and factor analysis. Based on the results of the analysis, it is known that people who have a preference for using the MRT mode are $98 \%$ with most of the characters being male, age range 25-35 years, type of private employee occupation, and income level $\geq$ Rp.4.000.000. The purpose of the trip to offices, and have travel needs for work. Furthermore, from the factor analysis, there are 17 groups of factors that's influence people's preferences in using the MRT mode, with the number 1 group factor having the highest level of eigenvalue variation.

Keywords: Preference, Factors Analysis, Mass Rapid Transit

\section{PENDAHULUAN}

Transportasi pada saat ini telah menjadi suatu kebutuhan mendasar yang sangat penting terutama untuk masyarakat perkotaan (Rasyid, 2015). Pertumbuhan kepemilikan kendaraan pribadi yang cukup tinggi menimbulkan berbagai macam permasalahan transportasi yakni salah satunya adalah kemacetan. Keberadaan angkutan umum yang memadai diharapkan dapat mengurai permasalahan transportasi yang terjadi. Di DKI Jakarta kebutuhan akan sistem transportasi umum yang memadai sangat dirasakan oleh masyarakat karena sering terjadinya kemacetan yang dapat merugikan berbagai aspek 
kehidupan (Ibrahim, 2010). Adapun pengertian umum angkutan umum Menurut Warpani, 1990, merupakan salah satu fasilitas transportasi yang dapat digunakan masyarakat dengan sistem sewa atau bayar (Purba, 2017). Namun terdapat berbagai faktor dan ciri masyarakat yang memilih menggunakan angkutan umum dalam kegiatan perjalanannya, dengan mempertimbangkan berbagai aspek dari pelayanan angkutan umum itu sendiri atau keperluan perjalanannya. Berdasarkan latar belakang tersebut maka penelitian ini dilakukan untuk mengetahui karakteristik masyarakat yang memiliki preferensi menggunakan angkutan umum dan faktor-faktor yang mempengaruhi preferensi menggunakan angkutan umum terutama moda MRT. terdapat beberapa penelitian yang telah dilakukan sebelumnya yang memiliki persamaan metode dengan penelitian ini.

Faktor-faktor yang mempengaruhi kualitas pelayanan moda Light Rapid Transit (LRT) Di Yogyakarta. Dimana memiliki tujuan untuk mengetahui faktor-faktor yang diharapkan oleh pengguna apabila LRT dioprasikan di Yogyakarta. Penelitian tersebut menggunakan analisis faktor dengan perimbangan variabel diantaranya, karakteristik responden, karakteristik perjalanan responden, dan tingkat pelayanan kualitatif, dengan hasil terdapat 3 katagori faktor yang mempengaruhi yang dimana berasal dari variabel tingkat pelayanan, diantaranya kelompok pertama yakni, faktor pelayanan keselamatan penumpang, kelompok kedua adalah faktor aksesibilitas dan kemudahan, kelompok ketiga adalah faktor keandalan (Dwitasari et al, 2016).

Penentuan faktor preferensi masyarakat terhadap moda transportasi didasarkan pada penelitian terdahulu tentang faktor penentu preferensi masyarakat Kota Cimahi terhadap moda transportasi Kereta Api. Penelitian tersebut menggunakan analisis faktor. Dimana dihasilkan 3 faktor teratas penentu preferensi masyarakat terhadap moda Kereta Api adalah, tarif, keselamatan, dan pengalaman dalam menggunakan moda tersebut (Raharjo et al, 2018).

Pada penelitian terdahulu tentang pemilihan moda transportasi umum menuju kampus, terdapat beberapa variabel pertimbangan untuk memilih moda transportasi yang akan digunakan. Pertimbangan variabel penelitian yang disebut dalam penelitian tersebut antara lain, jenis kelamin, kepemilikan kendaraan, kepemilikan SIM, uang saku, dan karakteristik perjalanan. Berdasarkan hasil analisis menggunakan analisis faktor terdapat 3 faktor yang mempengaruhi responden dalam memilih moda yang digunakan, faktor tersebut dari variabel karakteristik perjalanan, diantaranya, waktu tempuh, biaya tempuh, dan kemudahan dalam mencapai lokasi (Alkam et al, 2018).
Di, 2016. Melakukan penelitian tentang dampak moda Mass Rapid Transit terhadap keamanan public di San Fransisco. Penelitian tersebut menggunakan analisis faktor dengan hasil membentuk dua komponen kelompok faktor, dimana kelompok satu berisi variabel kepadatan penduduk, tingkat kemiskinan, tingkat penyewaan, tingkat tidak memiliki kendaraan, dan presentase kepemilikan 5 tahun terakhir. Sedangkan variabel yang berada pada kelompok dua adalah tingkat pekerjaan, dan tingkat pendidikan.

Saputra, et al, 2017. Melakukan penelitian tentang faktor-faktor yang mempengaruhi pemilihan moda menuju tempat kerja. Penelitian tersebut menggunakan analisis faktor. Berdasarkan hasil analisis terdapat 3 komponen faktor dari masingmasing variabel yakni, keamanan, kenyamanan, dan waktu tempuh, dimana dari variabel tersebut terdapat moda yang dipilih oleh responden dengan pertimbangan tersebut, diantaranya dari segi keamanan responden memilih bus kantor dan dari segi kenyamanan serta waktu tempuh responden memilih mobil pribadi.

Imtiyas, et al, 2019. Melakukan penelitian tentang faktor-faktor yang mempengaruhi pemilihan moda anak dalam mengakses sekolah dasar di Kota Surakarta. Penelitian tersebut menggunakan analisis faktor, berdasarkan hasil analisis diperoleh 7 kelompok faktor dimana kelompok faktor nomor 1 memiliki pengaruh paling besar dengan nilai $33.927 \%$. Variabel yang terdapat pada kelompok 1 diantaranya, struktur keluarga, ukuran keluarga, jenis pekerjaan orang tua, pendapatan orang tua, usia orang tua, dan jenis kelamin orang tua yang berperan. Disamping itu, hasil penelitian Aghnia dan Adtya (2016) menunjukkan bahwa terdapat enam faktor awal yang menjadi preferensi konsumen dalam menggunakan layanan jasa Go-Jek di kota Jakarta, antara lain: kepraktisan, tarif, kecepatan, keamanan, kepercayaan, kenyamanan. Penelitian ini juga menghasilkan satu faktor baru yang dinamakan faktor keunggulan bersaing Go-Jek serta faktor paling dominan yang menjadi preferensi konsumen dalam menggunakan layanan jasa Go-Jek yaitu faktor kenyamanan.

Laloma, et al, 2018, Melakukan Penelitan tentang Pengaruh Angkutan Online Terhadap Pemilihan Moda Transportasi Publik di Kota Manado (Studi Kasus: Trayek Malalayang - Pusat Kota). Penelitian ini menghasilkan Faktor kualitas pelayanan, aksesibilitas keterjangkauan, waktu, keamanan dan kenyamanan akan mempengaruhi pengguna untuk menggunakan angkutan kota.

Nur, et al, 2016, Melakukan Penelitian tentang

Studi Preferensi Transformasi Moda Angkutan 
Pribadi Berdasarkan Preferensi Angkutan Pribadi. Hasil penelitian berdasarkan analisa data diketahui yakni Preferensi Angkutan Pribadi perjalanan komuter yang tertinggi adalah indikator kenyamanan dalam hal keempukan tempat duduk, kemudian diteruskan dengan fasilitas tempat duduk dengan kesesuaian kondisi tubuh, sirkulasi udara, perilaku mengemudi, tingkat keamanan dari gangguan alam sangat aman, jaminan keamanan dari tindakan kriminal, kelengkapan kendaraan dalam hal alat keselamatan, jaminan keselamatan dari kecelakaan lalulintas, kenyamanan dalam hal kesesuaian umur kendaraan, Kedisiplinan berlalulintas dan yang terendah adalah fakor gengsi.

Salah satu contoh metode analisis yang digunakan dalam penelitian ini adalah berdasarkan penelitian terdahulu tentang Preferensi Konsumen Terhadap Transportasi Publik (Studi Kasus: BRT di Semarang). Penelitian tersebut menggunakan metode analisis faktor dengan hasil variabel yang terpilih adalah Harga, Kenyamanan, Kendala, Aksesbilitas dan Keamanan (Azali et al, 2018).

Berdasarkan beberapa penelitian yang telah dijabarkan dapat diketahui penelitian ini memiliki metode analisis yang menyerupai peneltian tersebut. Dengan tujuan penelitian ini antara lain:

1. mengetahui karakteristik masyarakat yang memiliki preferensi menggunakan moda MRT dan

2. mengetahui faktor-faktor yang mempengaruhi preferensi masyarakat dalam menggunakan moda MRT.

Berdasarkan tujuan tersebut diharapkan dapat diketahui karakteristik masyarakat yang memiliki preferensi menggunakan moda MRT dan faktor yang mempengaruhi preferensi tersebut.

\section{METODE PENELITIAN}

Tahapan penelitian untuk mengetahui faktorfaktor masyarakat dalam menggunakan moda MRT di
Kota Jakarta dapat digambarkan berdasarkan gambar 1.

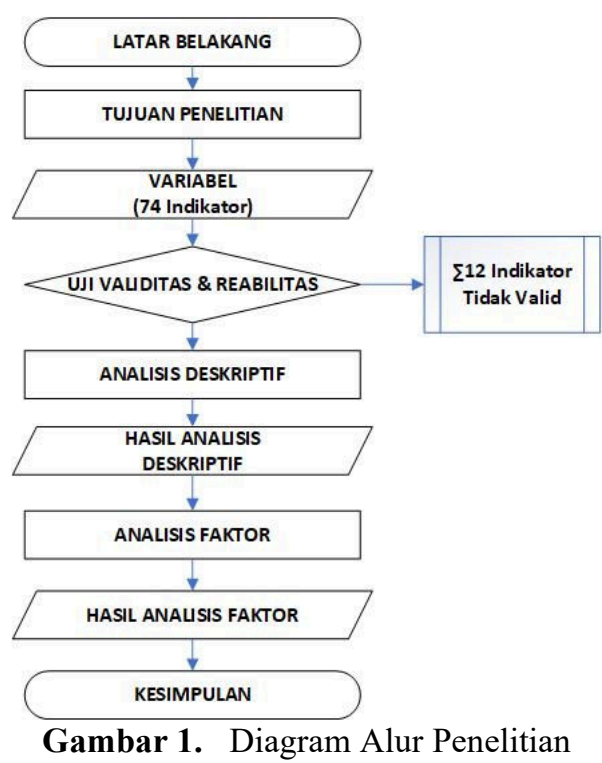

Berdasarkan Gambar 1 yang telah dijabarkan, dapat diketahui alur penelitian faktor-faktor yang mempengaruhi masyarakat dalam menggunakan moda MRT. Dimana terdapat 74 indikator variabel yang akan diteliti dengan metode analisis statistik deskriptif dan analisis faktor untuk mengetahui karakteristik masyarakat yang memiliki preferensi menggunakan moda MRT dan faktor-faktor yang mempengaruhi preferensi tersebut.

\section{Variabel Penelitian}

Penentuan variabel pada penelitian didasarkan pada tinjauan teori yang sebelumnya sudah dikumpulkan. Variabel-variabel tersebut digunakan untuk analisis statistik deskriptif dan analisis faktor. Variabel penelitian yang digunakan dapat dilihat pada Tabel 1.

Tabel 1. Variabel Penelitian

\begin{tabular}{|c|c|c|}
\hline Tujuan penelitian & Indikator & Sumber \\
\hline $\begin{array}{l}\text { Mengetahui karakteristik } \\
\text { yang memiliki preferensi } \\
\text { menggunakan moda MRT }\end{array}$ & $\begin{array}{ll}\text { - } & \text { Jenis kelamin (X1) } \\
\text { - } & \text { Usia (X2) } \\
\text { - } & \text { Pekerjaan (X3) } \\
\text { - } & \text { Penghasilan (X4) } \\
\text { - } & \text { Tujuan dan keperluan perjalanan (X5) } \\
\text { - } & \text { Frekuensi perjalanan responden (X6) }\end{array}$ & $\begin{array}{ll}\text { - } & \text { Choocarukul dan } \\
& \text { Sriroongvikrai, } 2013 \\
\text { - } & \text { Octavianti, 2012 } \\
\text { - } & \text { Kresnanto, 2013 } \\
\text { - } & \text { Nurdiansyah, 2015 }\end{array}$ \\
\hline $\begin{array}{l}\text { Mengetahui faktor-faktor } \\
\text { yang mempengaruhi } \\
\text { preferensi masyarakat } \\
\text { dalam menggunakan moda } \\
\text { MRT } \\
\text { 1. Tingkat kebersihan } \\
\text { dalam kereta }\end{array}$ & $\begin{array}{ll}\text { - } & \text { Ketersediaan tempat sampah dalam kereta (X7) } \\
\text { - } & \text { Keberadaan petugas kebersihan dalam kereta (X8) } \\
\text { - } & \text { Kondisi kebersihan dalam kereta (X9) } \\
\text { - } & \text { Ketersediaan alat pengeras suara (speaker) dalam kereta (X10) } \\
\text { - } & \text { Ketersediaan alat pengeras suara (speaker) dalam stasiun (X11) } \\
\text { - } & \text { Kondisi alat pengeras suara (speaker) dalam kereta (X12) } \\
\text { - } & \text { Kondisi alat pengeras suara (speaker) dalam stasiun (X13) } \\
\text { - } & \text { Ketersediaan papan informasi perjalanan dalam kereta (X14) }\end{array}$ & $\begin{array}{l}\text { Peraturan Menteri } \\
\text { Nomor } 98 \text { Tahun } \\
2013 \\
\text { - } \quad \text { Shoocarukul dan } \\
\text { Sriroovikrai, } 2013 \\
\text { - } \quad \text { Bahktiar, 2018 } \\
\text { - } \quad \text { Dwiryanti, } 2013 \\
\text { - } \quad \text { Medi, } 2017\end{array}$ \\
\hline
\end{tabular}




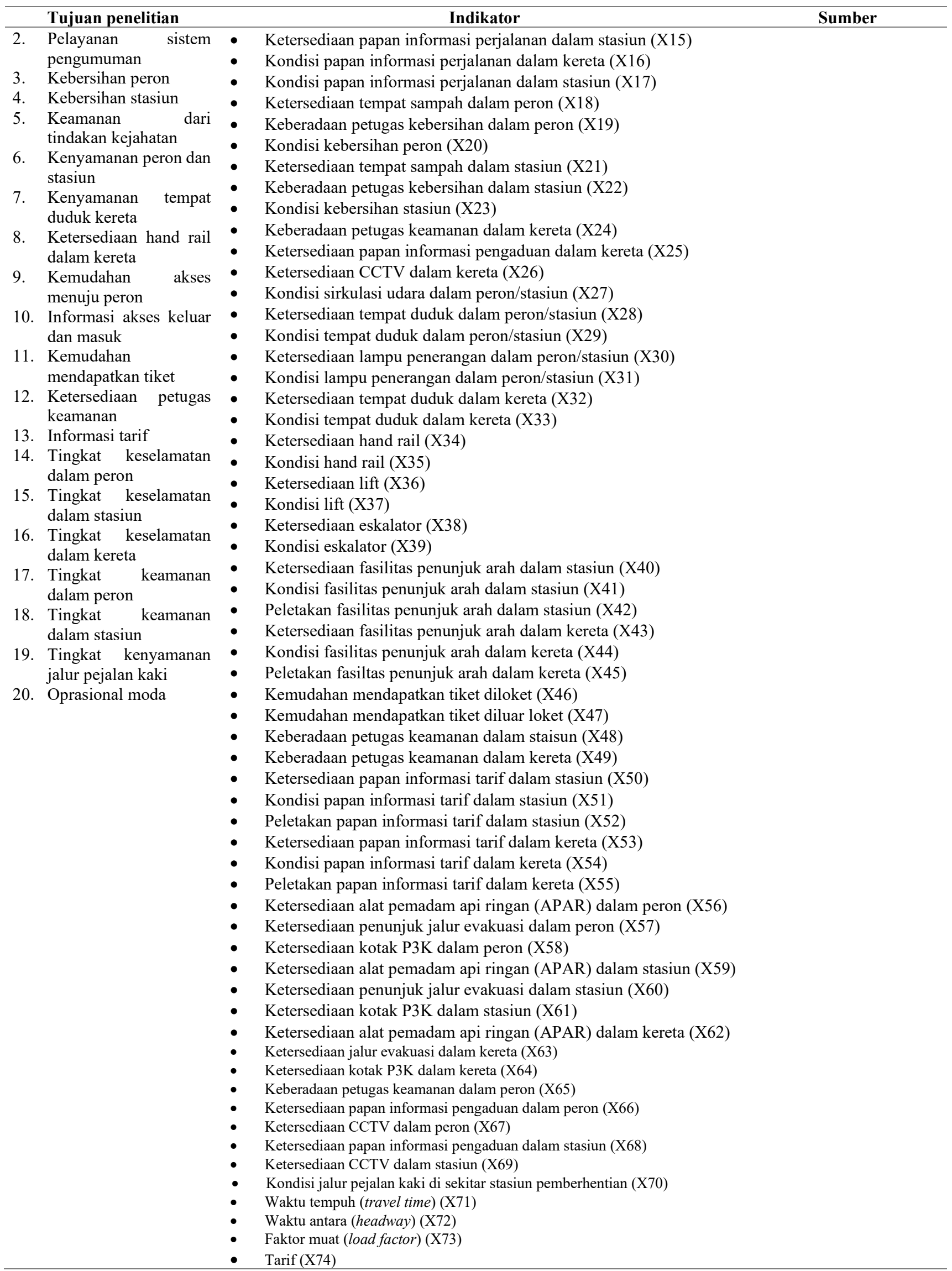

Sumber : Hasil Analisis 2020

Dapat diketahui terdapat 74 variabel yang akan dianalisis menggunakan analisis statistik deskriptif dan analisis faktor untuk mengetahui karakteristik pengguna moda MRT dan faktor-faktor yang 
mempengaruhi responden dalam menggunakan moda MRT.

\section{Pengumpulan Data}

Metode pengumpulan data dalam penelitian faktor-faktor yang mempengaruhi preferensi masyarakat dalam menggunakan moda Mass Rapid Transit (MRT) Kota Jakarta dilakukan dengan dua cara yaitu survei primer dan survei sekunder. Pengumpulan data primer dilakukan dengan melakukan observasi ke lokasi wilayah studi secara langsung, yakni memberikan kuisioner wawancara yang berkaitan dengan pemilihan responden terhadap moda MRT dan penilaian kinerja pelayanan dan oprsional moda MRT kepada responden terpilih.

Pengumpulan data sekunder dilakukan dengan cara pengambilan data pada instansi terkait yakni PT MRT Jakarta, serta mempelajari literatur-literatur yang berkaitan dengan penelitian yang akan dilakukan.

\section{Populasi dan Sampel Penelitian}

Metode penentuan sampel pada penelitian ini menggunakan Metode Slovin, dengan populasi adalah masyarakat DKI jakarta usia produktif. Jumlah masyarakat usia produktif DKI Jakarta sebesar 7.370.793 jiwa (BPS DKI Jakarta, 2018)

\section{Sampling}

Pada penelitian ini penentuan sampel menggunakan metode sampel slovin karena terdapat jumlah populasi yang dituju, dengan rumus sebagai berikut (Supriyanto, et all, 2017).

Keterangan:

$$
n=\frac{N}{1+N(e)^{2}}
$$

$\mathrm{n}$ = Jumlah sampel

$\mathrm{N}=$ Jumlah populasi (penduduk DKI Jakarta usia produktif)

$\mathrm{e}=$ persen kelonggaran ketidaktelitian dalam pengambilan sampel yang masih dapat ditolelir atau diinginkan $(5 \%)$.

Diketahui jumlah populasi yang diperoleh sebesar 7.370.793 yang akan ditentukan jumlah sampel menggunakan metode slovin. Berikut adalah jumlah sampel dari penelitian ini

$$
n=\frac{7.370 .793}{1+7.370 .793 \cdot(5 \%)^{2}}=399,97
$$

Berdasarkan hasil perhitungan sampel dalam penelitian ini akan diambil minimal sejumlah 399, 97 responden yang dibulatkan menjadi minimal 400 responden, Berikut ini adalah pembagian sampel yang akan diambil pada penelitian ini berdasar Kota Administrasi Provinsi DKI Jakarta.

\begin{tabular}{|c|c|}
\hline $\begin{array}{c}\text { Kota } \\
\text { Administrasi }\end{array}$ & Jumlah Sampel (Orang) \\
\hline Jakarta Pusat & 200 \\
\hline Jakarta Selatan & 200 \\
\hline Jakarta Utara & 100 \\
\hline Jakarta Timur & 100 \\
\hline Jakarta Barat & 100 \\
\hline Total & 700 Responden \\
\hline
\end{tabular}

Tabel 2. Pembagian Sampel

Sumber : Hasil Perhitungan 2019

Berdasarkan Rumus Slovin, jumlah sampel yang harus diwawancara oleh peneliti minimal sebesar 400 responden, Dapat diketahui jumlah 400 responden diprioritaskan pada wilayah yang telah dilayani oleh moda Mass Rapid Transit (MRT) itu sendiri yakni Jakarta Pusat dan Jakarta Selatan. Sehingga agar penyebaran sampel dapat mencakup seluruh wilayah DKI Jakarta maka peneliti menambahkan proporsi hasil sampel dari 400 menjadi 700 responden.

\section{Teknik Analisis}

Terdapat dua metode anaisis pada penelitian ini, dimana menggunakan metode analisis statistik deskriptif dan metode analisis faktor

1. Analisis Karakteristik pengguna moda MRT

Analisis karakteristik pengguna moda MRT digunakan untuk mengetahui karakteristik individu masyarakat yang memiliki preferensi menggunakan moda MRT. Analisis tersebut menggunakan metode analisis stastistik deskriptif.

2. Analisis faktor pengaruh preferensi Untuk mengetahui faktor yang mempengaruhi preferensi masyarakat dalam menggunakan moda MRT digunakan metode analisis faktor untuk mengetahui kelompok indikator dari variabel yang mempengaruhi preferensi masyarakat dalam menggunakan moda MRT.

\section{HASIL DAN PEMBAHASAN}

\section{Gambaran Umum}

Daerah Khusus Ibukota (DKI) Jakarta terletak di $6^{\circ} 12^{\prime}$ Lintang Selatan dan $106^{\circ} 48^{\prime}$ Bujur Timur. DKI Jakarta memilki luas sebesar $664,01 \mathrm{~km}^{2}$ dan merupakan kota metropolitan. Adapun batas-batas wilayah Provinsi DKI Jakarta adalah sebagai berikut:
Sebelah Timur : Provinsi Jawa Barat
Sebelah Barat : Provinsi Banten
Sebelah Selatan : Provinsi Jawa Barat
Sebelah Utara : Laut Jawa 


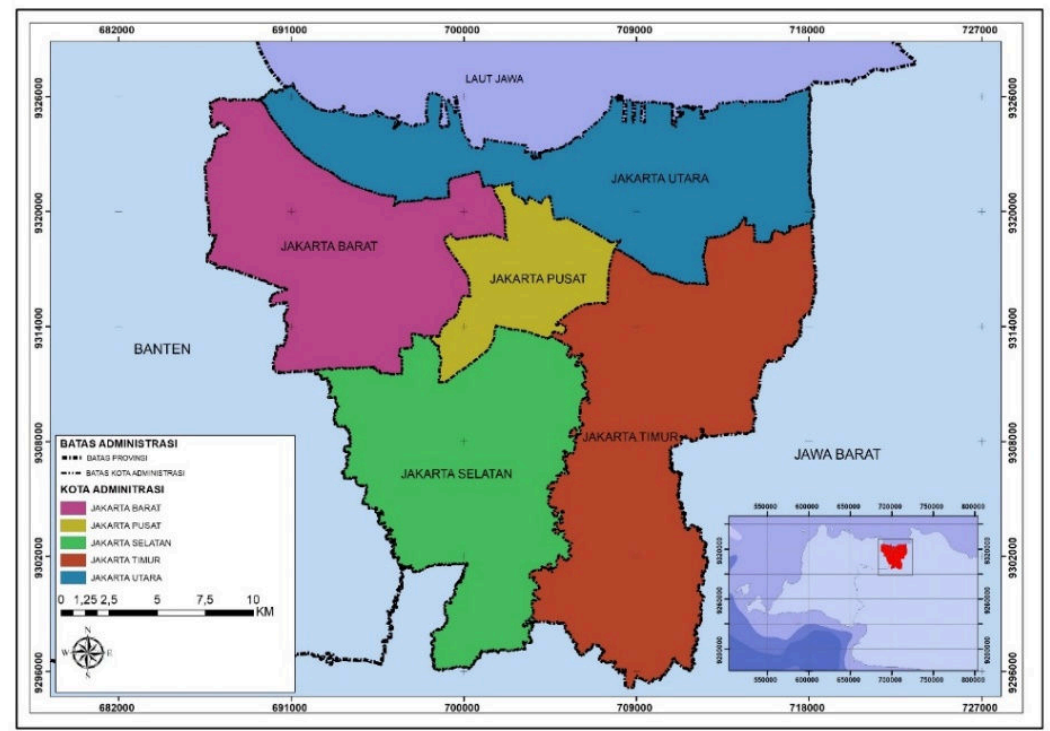

Gambar 2. Peta Administrasi DKI Jakarta

Responden yang dituju dalam penelitian ini merupakan masyarakat DKI Jakarta dengan usia produktif (15-64 tahun), yang memiliki pengalaman menggunakan moda MRT.

Sarana moda Mass Rapid Transit (MRT) Kota Jakarta memiliki 16 unit kereta dengan 6 gerbong pada setiap rangakaian unit kereta, rangkaian tersebut terdiri atas 4 gerbong regular dan 2 gerbong untuk ruang kemudi pada bagian depan dan belakang kereta. Dalam satu gerbong moda MRT terdapat 54 tempat duduk serta 100 hand rail sehingga dapat menampung sejumlah 154 penumpang setiap gerbongnya (Survei Primer, 2019), namun jumlah maksimal pada masingmasing gerbong sebesar 325 orang dengan jumlah daya tampung dalam satu unit rangkaian memiliki kapasitas 1950 penumpang. Berikut contoh gambar

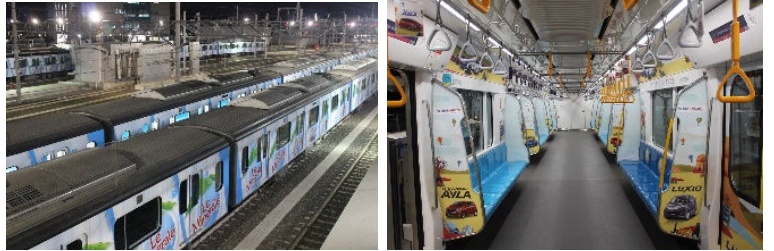

Gambar 3. Gambar Moda MRT Tampak Luar dan Tampak Dalam

Pada tahun 2019 baru beberapa jaringan saja yang telah terlayani moda MRT yakni koridor Selatan - Utara fase pertama dengan rute Lebak Bulus Bundaran HI. Moda Mass Rapid Transit (MRT) Jakarta ini rencananya akan diperluas jangkauan pelayanan rutenya sehingga dapat menunjang kebutuhan mobilitas masyarakat Kota Jakarta. tampak luar dan tampak dalam moda MRT Jakarta

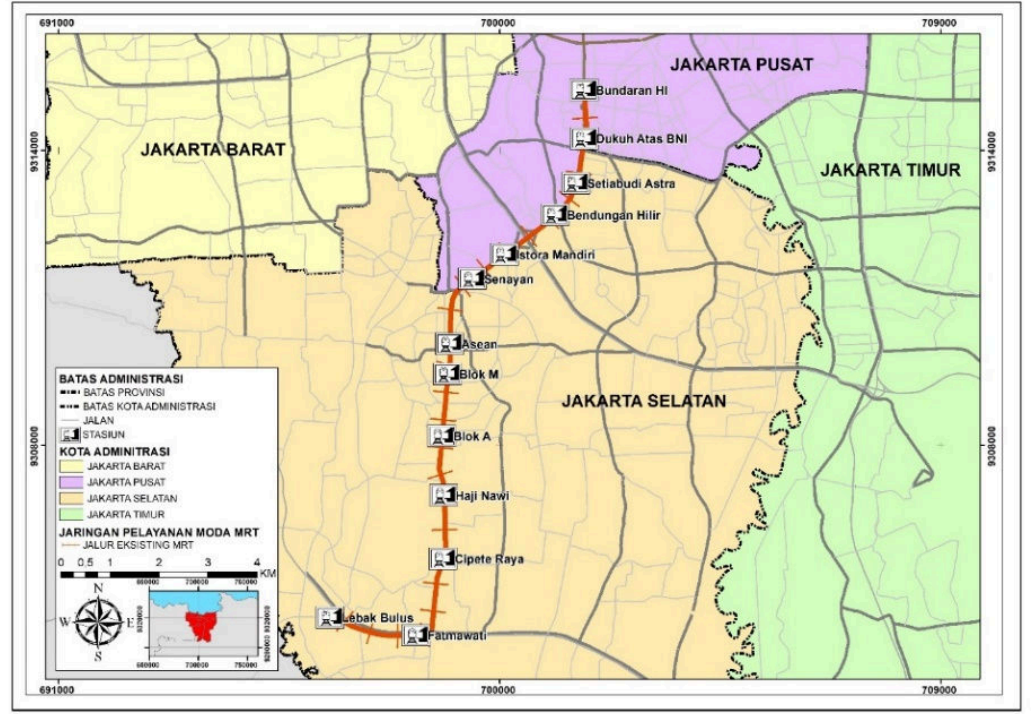

Gambar 4. Peta Rute Eksisting Moda MRT 


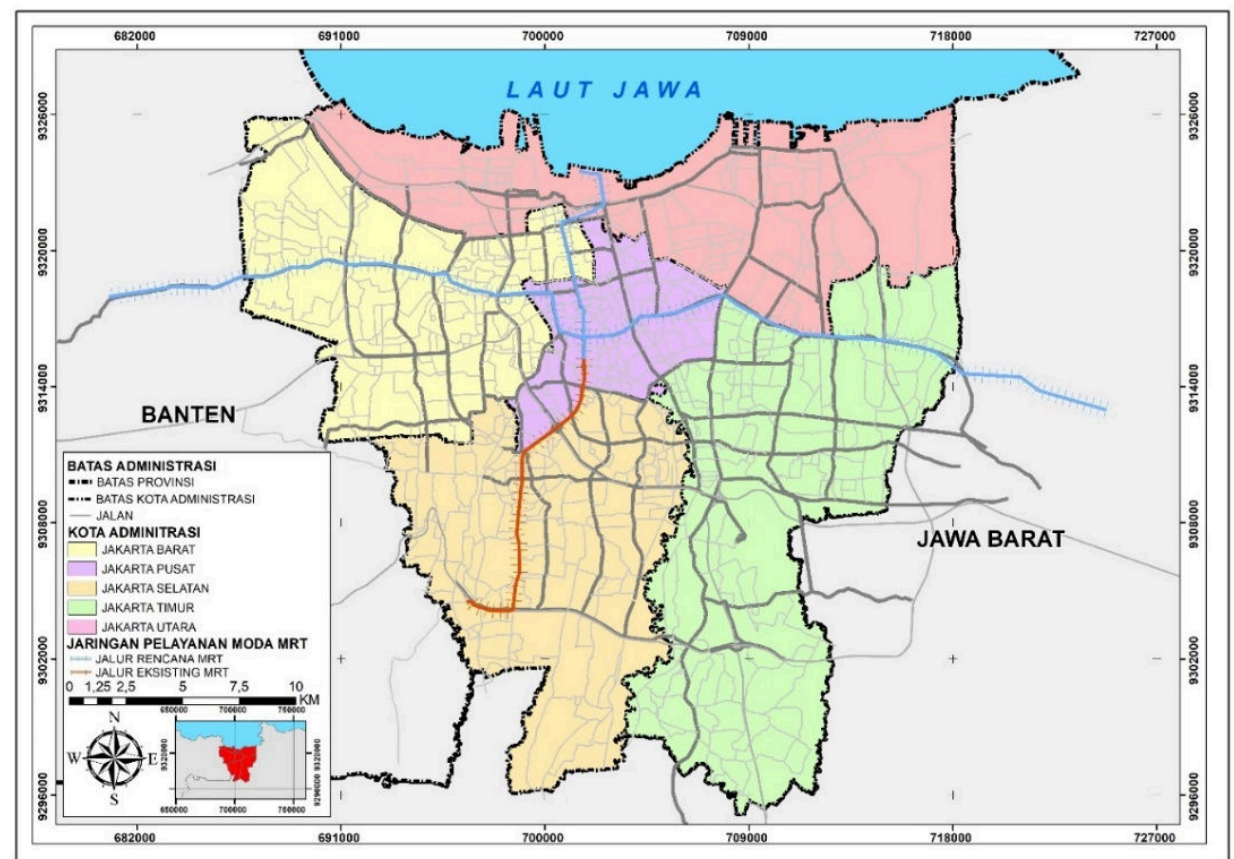

Gambar 5. Peta Rencana Rute Moda MRT

Berdasarkan Gambar 4 dan Gambar 5 dapat diketahui terdapat peta rute MRT yang telah beroprasi dan peta rencana perluasan jaringan moda MRT.

\section{Analisis Karakteristik Pengguna Moda MRT}

Responden yang difokuskan pada penelitian ini merupakan masyarakat DKI Jakarta dengan usia produktif (15-64 Tahun) yang memiliki pengalaman menggunakan moda MRT. Berikut karakteristik responden yang memiliki preferensi terhadap penggunaan moda MRT yang diolah menggunakan metode analisis statistik deskriptif.

Tabel 3. Presentase Karakteristik Responden

\begin{tabular}{|c|c|c|}
\hline Indikator & Kategori & Presentase \\
\hline \multirow{2}{*}{$\begin{array}{l}\text { Preferensi } \\
\text { penggunaan } \\
\text { moda MRT }\end{array}$} & Memilih moda MRT & $98 \%$ \\
\hline & Tidak memilih moda & $2 \%$ \\
\hline \multirow[t]{2}{*}{ Jenis kelamin } & Laki-laki & $56 \%$ \\
\hline & Perempuan & $44 \%$ \\
\hline \multirow[t]{5}{*}{ Usia } & 15-25 Tahun & $21 \%$ \\
\hline & 26-35 Tahun & $45 \%$ \\
\hline & 36-45 Tahun & $29 \%$ \\
\hline & 46-55 Tahun & $3 \%$ \\
\hline & 56-65 Tahun & $1 \%$ \\
\hline \multirow[t]{5}{*}{ Jenis pekerjaan } & PNS & $18 \%$ \\
\hline & Pegawai swasta & $55 \%$ \\
\hline & Pelajar/mahasiswa & $15 \%$ \\
\hline & Wiraswasta & $11 \%$ \\
\hline & Lainnya & $1 \%$ \\
\hline \multirow[t]{4}{*}{ Penghasilan } & $\leq \mathrm{Rp} .1 .000 .000$ & $15 \%$ \\
\hline & \multirow{2}{*}{\multicolumn{2}{|c|}{$\begin{array}{l}\geq \text { Rp.1.000.000 } \\
<\text { Rp. } 2.000 .000\end{array}$}} \\
\hline & & \\
\hline & \multicolumn{2}{|l|}{$\begin{array}{l}\geq \text { Rp.2.000.000 } \\
<\text { Rp.3.000.000 }\end{array}$} \\
\hline
\end{tabular}

\begin{tabular}{|c|c|c|}
\hline Indikator & Kategori & Presentase \\
\hline & $\begin{array}{l}\geq \text { Rp.3.000.000 } \\
<\text { Rp.4.000.000 }\end{array}$ & $18 \%$ \\
\hline & $\geq$ Rp.4.000.000 & $61 \%$ \\
\hline \multirow{5}{*}{$\begin{array}{l}\text { Tujuan } \\
\text { perjalanan }\end{array}$} & Perkantoran & $44 \%$ \\
\hline & $\begin{array}{l}\text { Instansi pendidikan } \\
\text { (Sekolah/Universitas) }\end{array}$ & $13 \%$ \\
\hline & Tempat wisata & $15 \%$ \\
\hline & $\begin{array}{l}\text { Pasar/pusat } \\
\text { perbelanjaan }\end{array}$ & $27 \%$ \\
\hline & Lainnya & $1 \%$ \\
\hline \multirow{5}{*}{$\begin{array}{l}\text { Keperluan } \\
\text { perjalanan }\end{array}$} & Bekerja & $45 \%$ \\
\hline & $\begin{array}{l}\text { Pendidikan } \\
\text { (Sekolah/Kuliah) }\end{array}$ & $13 \%$ \\
\hline & Wisata & $15 \%$ \\
\hline & Keperluan usaha & $7 \%$ \\
\hline & Berbelanja & $20 \%$ \\
\hline \multirow{3}{*}{$\begin{array}{l}\text { Frekuensi } \\
\text { perjalan } \\
\text { responden }\end{array}$} & 1-5 kali seminggu & $71 \%$ \\
\hline & 6-10 kali seminggu & $19 \%$ \\
\hline & 11-15 kali seminggu & $9 \%$ \\
\hline \multirow{2}{*}{$\begin{array}{l}\text { Frekuensi } \\
\text { penggunaan } \\
\text { moda MRT }\end{array}$} & 1-5 kali seminggu & $76 \%$ \\
\hline & 6-10 kali seminggu & $24 \%$ \\
\hline
\end{tabular}

Sumber: Hasil Survei (2019)

Berdasarkan Tabel 4 dapat diketahui bahwa dari 700 responden sebesar $98 \%$ memiliki preferensi dalam menggunakan moda MRT, dengan dominasi karakteristik yang meliputi, jenis kelamin laki-laki, rentang usia 26-35 Tahun, jenis pekerjaan pegawai swasta, tingkat penghasilan $\geq$ Rp.4.000.000, tujuan perjalanan menuju perkantoran, keperluan perjalanan untuk bekerja, dan frekuensi penggunaan moda MRT 1-5 kali dalam seminggu. 


\section{Analisis Faktor Pengaruh Preferensi Masyarakat Dalam Memilih MRT}

Analisis faktor pengaruh preferensi masyarakat dalam memilih MRT diolah menggunakan analisis faktor, maka data survei terlebih dahulu dilakukan uji validitas dan reliabilitas untuk mengetahui indikator variabel tersebut valid dan reliabel. Namun terdapat beberapa indikator yang tidak valid. Berikut merupakan tabel indikator variabel yang tidak valid.

Tabel 4. Indikator Variabel Tidak Valid

$$
\text { Jenis kelamin (X1) }
$$

Jenis Pekerjaan (X3)

Penghasilan (X4)

Keberadaan petugas keamanan dalam kereta (X24)

Ketersediaan papan informasi pengaduan dalam kereta (X25)

Ketersediaan CCTV dalam kereta (X26)

Indikator Tidak Keberadaan petugas keamanan dalam Valid

\section{kereta (X49)}

Ketersediaan papan informasi tarif dalam stasiun (X50)

Kondisi papan informasi tarif dalam stasiun (X51)

Peletakan papan informasi tarif dalam stasiun (X52)

Ketersediaan jalur evakuasi dalam peron (X57)

Sumber : Hasil Analisis 2020

Waktu antara (Headway) (X72)

Berdasarkan Tabel 5 dapat diketahui bahwa dari 74 indikator variabel terdapat beberapa indikator variabel yang tidak valid. Hal ini dikarenakan pada

Tabel 6. Table of Variant tabel distribusi nilai $\mathrm{R}$ dengan nilai 0,074 untuk total 700 responden dan nilai signifikansi 5\%. Oleh karena itu, indikator-indikator tersebut tidak dilanjutkan pada tahap analisis berikutnya.

Kemudian Hasil Uji Reliabilitas dapat diketahui nilai dari Cronbach Alpha seluruh indikator variabel dalam penelitian ini memiliki nilai $>0,70$, sehingga seluruh indikator dari masing-masing variabel pada penelitian ini reliabel dan data yang digunakan konsisten dari setiap pengukurannya.

\section{Analisis Faktor}

Setelah dilakukan uji validitas dan reliabilitas dari seluruh indikator variabel, kemudian dilakukan analisis faktor untuk mengetahui faktor-faktor yang mempengaruhi preferensi responden dalam menggunakan moda MRT. Berikut adalah hasil analisis faktor yang telah dilakukan.

Tabel 5. Uji KMO and Bartlett's Test

\begin{tabular}{|c|c|c|}
\hline $\begin{array}{l}\text { Kaiser-Meyer-Olkin } \\
\text { Sampling Adequacy }\end{array}$ & Measure & .789 \\
\hline \multirow[t]{3}{*}{$\begin{array}{l}\text { Bartlett's Test of } \\
\text { Sphericity }\end{array}$} & $\begin{array}{l}\text { Approx. } \\
\text { Square }\end{array}$ & 36379.429 \\
\hline & $\mathrm{df}$ & 1891 \\
\hline & Sig. & .000 \\
\hline
\end{tabular}

Berdasar Tabel 6 maka dapat diketahui bahwa dari hasil KMO and Bartlett's Test diperoleh hasil 0,789 dengan nilai signifikansi 0,000, hal tersebut berarti model cocok dan dapat menjelaskan indikator yang dilakukan menggunakan analisis faktor sebesar 78,9\% dengan nilai signifikansi sebesar 0,000 .

\begin{tabular}{|c|c|c|c|c|c|c|c|c|c|}
\hline \multirow[b]{2}{*}{$\begin{array}{c}\text { Compon } \\
\text { ent }\end{array}$} & \multicolumn{3}{|c|}{ Initial Eigenvalues } & \multicolumn{3}{|c|}{ Extraction Sums of Squared Loadings } & \multicolumn{3}{|c|}{ Rotation Sums of Squared Loadings } \\
\hline & Total & $\begin{array}{c}\text { \% of } \\
\text { Variance }\end{array}$ & $\begin{array}{c}\text { Cumulative } \\
\%\end{array}$ & Total & $\begin{array}{c}\text { \% of } \\
\text { Variance }\end{array}$ & Cumulative \% & Total & $\begin{array}{c}\text { \%o of } \\
\text { Variance }\end{array}$ & Cumulative \% \\
\hline 1 & 7.940 & 12.807 & 12.807 & 7.940 & 12.807 & 12.807 & 7.333 & 11.827 & 11.827 \\
\hline 2 & 7.134 & 11.507 & 24.313 & 7.134 & 11.507 & 24.313 & 4.186 & 6.752 & 18.579 \\
\hline 3 & 4.418 & 7.125 & 31.439 & 4.418 & 7.125 & 31.439 & 4.063 & 6.554 & 25.133 \\
\hline 4 & 3.541 & 5.711 & 37.150 & 3.541 & 5.711 & 37.150 & 3.321 & 5.356 & 30.489 \\
\hline 5 & 3.012 & 4.859 & 42.009 & 3.012 & 4.859 & 42.009 & 3.212 & 5.181 & 35.670 \\
\hline 6 & 2.674 & 4.313 & 46.322 & 2.674 & 4.313 & 46.322 & 2.869 & 4.627 & 40.297 \\
\hline 7 & 2.029 & 3.272 & 49.594 & 2.029 & 3.272 & 49.594 & 2.676 & 4.316 & 44.613 \\
\hline 8 & 1.915 & 3.088 & 52.682 & 1.915 & 3.088 & 52.682 & 2.393 & 3.860 & 48.473 \\
\hline 9 & 1.728 & 2.787 & 55.470 & 1.728 & 2.787 & 55.470 & 2.192 & 3.536 & 52.009 \\
\hline 10 & 1.472 & 2.374 & 57.844 & 1.472 & 2.374 & 57.844 & 1.877 & 3.027 & 55.036 \\
\hline 11 & 1.451 & 2.341 & 60.184 & 1.451 & 2.341 & 60.184 & 1.721 & 2.776 & 57.812 \\
\hline 12 & 1.417 & 2.286 & 62.470 & 1.417 & 2.286 & 62.470 & 1.700 & 2.742 & 60.553 \\
\hline 13 & 1.297 & 2.092 & 64.562 & 1.297 & 2.092 & 64.562 & 1.688 & 2.722 & 63.276 \\
\hline 14 & 1.218 & 1.964 & 66.526 & 1.218 & 1.964 & 66.526 & 1.499 & 2.418 & 65.694 \\
\hline 15 & 1.171 & 1.888 & 68.414 & 1.171 & 1.888 & 68.414 & 1.371 & 2.211 & 67.905 \\
\hline 16 & 1.132 & 1.825 & 70.240 & 1.132 & 1.825 & 70.240 & 1.308 & 2.109 & 70.014 \\
\hline 17 & 1.070 & 1.725 & 71.965 & 1.070 & 1.725 & 71.965 & 1.210 & 1.951 & 71.965 \\
\hline
\end{tabular}

Sumber: Hasil Analisa SPSS 2020

Berdasarkan Tabel 7 diketahui terdapat 17 kelompok faktor dimana kelompok faktor nomor 1 merupakan kelompok yang memiliki angka variasi tertinggi yakni
12.807. Berikut adalah hasil analisis faktor yang terbagi menjadi 17 kelompok dari masing-masing variabel yang diberikan nama baru. 
Tabel 7. Kelompok Faktor Terpilih

\begin{tabular}{|c|c|c|c|}
\hline Kelompok & Nama Kelompok Variabel & Indikator & $\begin{array}{c}\text { Koefisien } \\
\text { faktor }\end{array}$ \\
\hline \multirow[t]{9}{*}{ Kelompok 1} & \multirow{9}{*}{$\begin{array}{lll}\text { Tangkat kebersihan } & \text { dan } \\
\text { kenyamanan } & & \end{array}$} & Kondisi kebersihan dalam kereta $\left(\mathrm{X}_{9}\right)$ & 0,849 \\
\hline & & Kondisi kebersihan stasiun $\left(\mathrm{X}_{23}\right)$ & 0,912 \\
\hline & & Ketersediaan tempat duduk dalam kereta $\left(\mathrm{X}_{32}\right)$ & 0,926 \\
\hline & & Ketersediaan hand rail dalam kereta $\left(\mathrm{X}_{34}\right)$ & 0,720 \\
\hline & & Ketersediaan lift dalam stasiun $\left(\mathrm{X}_{36}\right)$ & 0.907 \\
\hline & & Kondisi papan penunjuk arah dalam stasiun $\left(\mathrm{X}_{41}\right)$ & 0,941 \\
\hline & & Kemudahan memperoleh tiket diloket $\left(\mathrm{X}_{46}\right)$ & 0,875 \\
\hline & & Ketersediaan jalur evakuasi dalam kereta $\left(\mathrm{X}_{63}\right)$ & 0,982 \\
\hline & & Kondisi jalur pejalan kaki disekitar stasiun pemberhentian $\left(\mathrm{X}_{70}\right)$ & 0,938 \\
\hline \multirow[t]{4}{*}{ Kelompok 2} & \multirow{4}{*}{$\begin{array}{l}\text { Kondisi informasi dalam kereta } \\
\text { dan stasiun }\end{array}$} & Kondisi speaker dalam kereta $\left(\mathrm{X}_{12}\right)$ & 0,917 \\
\hline & & Kondisi speaker dalam stasiun $\left(\mathrm{X}_{13}\right)$ & 0,930 \\
\hline & & Kondisi papan informasi perjalanan dalam kereta $\left(\mathrm{X}_{16}\right)$ & 0,947 \\
\hline & & Kondisi papan informasi perjalanan dalam stasiun $\left(\mathrm{X}_{17}\right)$ & 0,891 \\
\hline \multirow[t]{5}{*}{ Kelompok 3} & \multirow[t]{5}{*}{ Informasi keamanan } & Kondisi papan informasi penunjuk arah dalam kereta $\left(\mathrm{X}_{44}\right)$ & 0,875 \\
\hline & & Keberadaan petugas keamanan dalam stasiun $\left(\mathrm{X}_{48}\right)$ & 0,906 \\
\hline & & Keberadaan petugas keamanan dalam peron $\left(\mathrm{X}_{65}\right)$ & 0,923 \\
\hline & & Ketersediaan CCTV dalam peron $\left(\mathrm{X}_{67}\right)$ & 0,856 \\
\hline & & Ketersediaan CCTV dalam stasiun $\left(\mathrm{X}_{69}\right)$ & 0,814 \\
\hline \multirow[t]{5}{*}{ Kelompok 4} & \multirow{5}{*}{$\begin{array}{l}\begin{array}{l}\text { Kebersihan dan } \\
\text { perjalanan }\end{array} \\
\end{array}$} & Ketersediaan tempat sampah dalam stasiun $\left(\mathrm{X}_{21}\right)$ & 0,640 \\
\hline & & Keberadaan petugas kebersihan dalam stasiun $\left(\mathrm{X}_{22}\right)$ & 0,663 \\
\hline & & Ketersediaan lampu penerangan dalam peron $\left(\mathrm{X}_{30}\right)$ & 0,621 \\
\hline & & Kondisi tempat duduk dalam kereta $\left(\mathrm{X}_{33}\right)$ & 0,697 \\
\hline & & Kondisi lampu penerangan dalam peron $\left(\mathrm{X}_{31}\right)$ & 0,542 \\
\hline \multirow[t]{4}{*}{ Kelompok 5} & \multirow[t]{4}{*}{ Keselamatan dan informasi } & Ketersediaan kotak P3K dalam peron $\left(\mathrm{X}_{58}\right)$ & 0,875 \\
\hline & & Ketersediaan kotak P3K dalam stasiun $\left(\mathrm{X}_{61}\right)$ & 0,823 \\
\hline & & Ketersediaan kotak P3K dalam kereta $\left(\mathrm{X}_{64}\right)$ & 0,841 \\
\hline & & Ketersediaan papan informasi pengaduan dalam peron $\left(\mathrm{X}_{66}\right)$ & 0,859 \\
\hline \multirow[t]{3}{*}{ Kelompok 6} & \multirow[t]{3}{*}{ Informasi dalam kereta } & Ketersediaan papan informasi tarif dalam kereta $\left(\mathrm{X}_{53}\right)$ & 0,838 \\
\hline & & Kondisi papan informasi tarif dalam kereta $\left(\mathrm{X}_{54}\right)$ & 0,953 \\
\hline & & Peletakan papan informasi tarif dalam kereta $\left(\mathrm{X}_{55}\right)$ & 0,956 \\
\hline \multirow[t]{3}{*}{ Kelompok 7} & \multirow{3}{*}{$\begin{array}{l}\text { Aksesibilitas dalam kereta dan } \\
\text { stasiun }\end{array}$} & Kondisi lift $\left(\mathrm{X}_{37}\right)$ & 0,567 \\
\hline & & Ketersediaan papan penunjuk arah dalam stasiun $\left(\mathrm{X}_{40}\right)$ & 0,813 \\
\hline & & Ketersediaan papan penunjuk arah dalam kereta $\left(\mathrm{X}_{43}\right)$ & 0,805 \\
\hline \multirow[t]{3}{*}{ Kelompok 8} & \multirow[t]{3}{*}{ Aspek keselamatan } & Ketersediaan APAR dalam peron $\left(\mathrm{X}_{56}\right)$ & 0,685 \\
\hline & & Ketersediaan APAR dalam stasiun $\left(\mathrm{X}_{59}\right)$ & 0,913 \\
\hline & & Ketersediaan APAR dalam kereta $\left(\mathrm{X}_{62}\right)$ & 0,906 \\
\hline \multirow[t]{2}{*}{ Kelompok 9} & \multirow[t]{2}{*}{ Ketersediaan papan informasi } & Ketersediaan papan informasi perjalanan dalam kereta $\left(\mathrm{X}_{14}\right)$ & 0,854 \\
\hline & & Ketersediaan papan informasi perjalanan dalam stasiun $\left(\mathrm{X}_{15}\right)$ & 0,862 \\
\hline \multirow[t]{3}{*}{ Kelompok 10} & \multirow[t]{3}{*}{ Kebersihan dan informasi } & Ketersediaan tempat sampah dalam kereta $\left(\mathrm{X}_{7}\right)$ & 0,689 \\
\hline & & Keberadaan petugas kebersihan dalam kereta $\left(\mathrm{X}_{8}\right)$ & 0,705 \\
\hline & & Ketersediaan speaker dalam stasiun $\left(\mathrm{X}_{11}\right)$ & 0,534 \\
\hline \multirow[t]{2}{*}{ Kelompok 11} & Aspek kenyamanan & Ketersediaan tempat duduk dalam peron $\left(\mathrm{X}_{28}\right)$ & 0,646 \\
\hline & & Faktor muat (load factor) $\left(\mathrm{X}_{73}\right)$ & 0,706 \\
\hline Kelompok 12 & Kebersihan peron & Ketersediaan tempat sampah dalam peron $\left(\mathrm{X}_{18}\right)$ & 0,667 \\
\hline & & Keberadaan petugas kebersihan dalam peron $\left(\mathrm{X}_{19}\right)$ & 0,570 \\
\hline Kelompok 13 & Informasi dan waktu tempuh & Peletakan papan penunjuk arah dalam kereta $\left(\mathrm{X}_{45}\right)$ & 0,809 \\
\hline & & Waktu tempuh $\left(\mathrm{X}_{71}\right)$ & 0,713 \\
\hline Kelompok 14 & $\begin{array}{l}\text { Kuantitas speaker informasi dalam } \\
\text { kereta }\end{array}$ & Ketersediaan speaker dalam kereta $\left(\mathrm{X}_{10}\right)$ & 0,696 \\
\hline Kelompok 15 & Aksesibilitas dan biaya perjalanan & Ketersediaan eskalator $\left(\mathrm{X}_{38}\right)$ & 0,616 \\
\hline & & Tarif $\left(\mathrm{X}_{74}\right)$ & 0,635 \\
\hline Kelompok 16 & Tingkat kebersihan peron & Kondisi kebersihan peron $\left(\mathrm{X}_{20}\right)$ & 0,755 \\
\hline Kelompok 17 & Aspek keselamatan stasiun & Ketersediaan jalur evakuasi dalam stasiun $\left(\mathrm{X}_{60}\right)$ & 0,721 \\
\hline
\end{tabular}

Sumber : Hasil Analisis (2020)

Berdasarkan Tabel 8 dapat diketahui terdapat 17 kelompok faktor dimana masing-masing kelompok terdapat indikator-indikator yang mempengaruhi preferensi responden dalam menggunakan moda
MRT dengan kelompok faktor nomor 1 merupakan kelompok yang memiliki tingkat variasi tertinggi. indikator tersebut diurutkan dari nilai terbesar diantaranya, ketersediaan jalur evakuasi dalam kereta (X63), kondisi papan penunjuk arah dalam stasiun 
(X41), kondisi jalur pejalan kaki disekitar stasiun pemberhentian (X70), ketersediaan tempat duduk dalam kereta (X32), kondisi kebersihan stasiun (X23), kemudahan memperoleh tiket diloket (X46), kondisi kebersihan dalam kereta (X9), dan ketersediaan hand rail dalam kereta (X34)

\section{KESIMPULAN}

Berdasarkan hasil dan pembahasan yang telah dipaparkan, dapat diambil kesimpulan sebagai berikut:

1. Karakteristik responden yang memiliki preferensi terhadap moda MRT didominasi oleh responden dengan jenis kelamin Laki-laki, rentang usia 26-35 tahun, jenis pekerjaan pegawai swasta, tingkat penghasilan $\geq$ Rp.4.000.000, tujuan perjalanan menuju perkantoran, keperluan perjalanan untuk bekerja, dan frekuensi penggunaan moda MRT responden sebanyak 1-5 kali dalam seminggunya.

2. Faktor-faktor yang mempangaruhi preferensi responden terhadap pemilihan moda MRT yang digunakan dengan metode analisis faktor, dimana diperoleh 17 kelompok faktor yang mempengaruhi preferensi responden dengan kelompok faktor nomor 1 merupakan kelompok yang memiliki tingkat presentase eigen value tertinggi dari nama variabel baru yang diberikan yakni tingkat kebersihan dan kenyamanan.

\section{DAFTAR PUSTAKA}

Alkam, R. B., \& Said, L. B. (2018). Pemilihan Moda Transportasi Menuju Kampus Mahasiswa Universitas Muslim Indonesia. Jurnal Transportasi, 18(3), 201-210.

Azali, I., Gunanto, E. Y. A., \& SBM, N. (2018). Preferensi Konsumen Terhadap Transportasi Publik (Studi Kasus Bus Rapid Transit (BRT) Kota Semarang). Media Ekonomi Dan Manajemen, 33(1).

Di, W. (2017). The Impact of Mass Transit on Public Security - A Study of Bay Area Rapid Transit in San Francisco. Transportation Research Procedia, 25, 3233-3252.

Harish, A. G., \& Wardhana, A. (2016). Analisis Faktor-Faktor Pembentuk Preferensi Konsumen Go-Jek Di Kota Jakarta the Analysis of Factors Forming Consumer Preference Go-Jek in Jakarta City. E-Proceeding of Management, 3(2), 1-7.

Imtiyas, S., Putri, R. A., \& Rini, E. F. (2019). Faktorfaktor yang Mempengaruhi Pemilihan Moda
Bermotor Anak dalam Mengakses Sekolah Dasar di Kota Surakarta. Region: Jurnal Pembangunan Wilayah Dan Perencanaan Partisipatif, 14(1), 13.

Intan Kusumawardhani. (2016). Faktor - Faktor yang Mempengaruhi Kualitas Hidup. Jurnal Transportasi Multimoda, 4(2), 2-3. Retrieved from http://eprints.poltekkesjogja.ac.id/239/

Kresnanto, N. C. (2013). ANGKUTAN UMUM PERKOTAAN (Studi Kasus: Angkutan Perkotaan Yogyakarta). Jurnal Teknik, 3(2), 122-132.

Laloma, A., Rompis, S. Y. R., \& Jefferson, L. (2018). Pengaruh Angkutan Online Terhadap Pemilihan Moda Transportasi Publik Di Kota Manado (Studi Kasus: Trayek Malalayang - Pusat Kota). Jurnal Sipil Statik, 6(8), 541-552.

Nur, N. K., Samang, L., Ramli, M. I., Program, M., Teknik, D., Hasanuddin, U. (2016). Studi Preferensi Berdasarkan Preferensi Angkutan Pribadi. Jurnal Ilmiah Techno Entrepreneur Acta, 2(April), 1-10.

Raharjo, R. D., Amaliah, I., \& Haviz, M. (2018). (Studi Kasus: Kereta Ekonomi Lokal Bandung Raya). Prosiding Ilmu Ekonomi, Volume 4, 1-8.

Rahmad, S., Anggraini, R., \& Isya, M. (2017). Analisa Faktor-faktor yang Mempengaruhi Pemilihan Moda Transportasi Penduduk Kerja di Kecamatan Sukmajaya Depok Menuju Tempat Kerja dengan Menggunakan Metode Analytic Hierarchy Process. Jurnal Teknik Sipil Universitas Syiah Kuala, 1(1), 199-218.

Sriroongvikrai, K., \& Choocharukul, K. (2013). Multivariate Analysis of Customer Satisfaction: A Case Study of Bangkok's Mass Rapid Transit (MRT) Passengers. Journal of the Eastern Asia Society for Transportation Studies, 10, 12581269. 